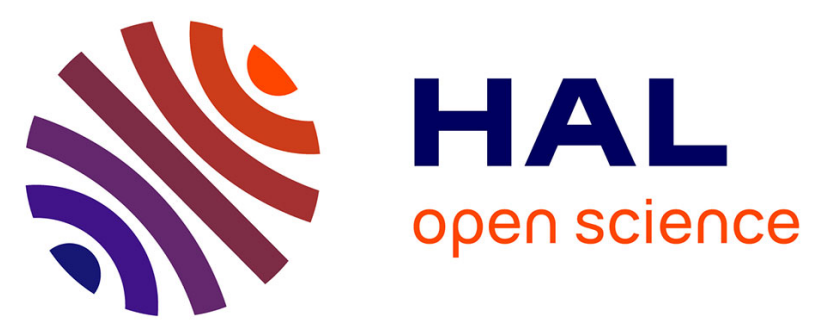

\title{
Equivalent Absorption Capacity (EAC) concept applied to the absorption of hydrophobic VOCs in a water/PDMS mixture
}

Eric Dumont, Annabelle Couvert, Abdeltif Amrane, Catherine Couriol, Guillaume Darracq, Pierre Le Cloirec

\section{To cite this version:}

Eric Dumont, Annabelle Couvert, Abdeltif Amrane, Catherine Couriol, Guillaume Darracq, et al.. Equivalent Absorption Capacity (EAC) concept applied to the absorption of hydrophobic VOCs in a water/PDMS mixture. Chemical Engineering Journal, 2016, 287, pp.205-216. 10.1016/j.cej.2015.11.020 . hal-01240654

HAL Id: hal-01240654

https://hal-univ-rennes1.archives-ouvertes.fr/hal-01240654

Submitted on 5 Jan 2016

HAL is a multi-disciplinary open access archive for the deposit and dissemination of scientific research documents, whether they are published or not. The documents may come from teaching and research institutions in France or abroad, or from public or private research centers.
L'archive ouverte pluridisciplinaire HAL, est destinée au dépôt et à la diffusion de documents scientifiques de niveau recherche, publiés ou non, émanant des établissements d'enseignement et de recherche français ou étrangers, des laboratoires publics ou privés. 


\title{
Equivalent Absorption Capacity (EAC) concept applied to the absorption of hydrophobic VOCs in a water/PDMS mixture
}

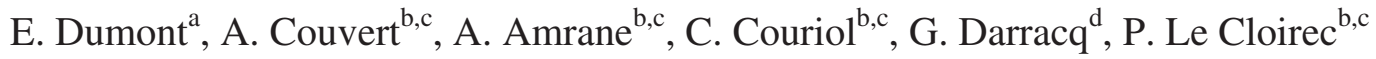 \\ a'UMR CNRS 6144 GEPEA, L'UNAM, École des Mines de Nantes, La Chantrerie, 4 rue Alfred \\ Kastler, B.P. 20722, 44307 Nantes Cedex 3, France \\ eric.dumont@mines-nantes.fr \\ bÉcole Nationale Supérieure de Chimie de Rennes, CNRS, UMR 6226, 11 allée de Beaulieu, CS \\ 50837, 35708 Rennes Cedex 7, France \\ ${ }^{\mathrm{c}}$ Université Européenne de Bretagne, France \\ annabelle.couvert@ensc-rennes.fr \\ abdeltif.amrane@ensc-rennes.fr \\ catherine.couriol@univ-rennes1.fr \\ pierre.le-cloirec@ensc-rennes.fr \\ ${ }^{\mathrm{d}}$ Eau de Paris - DRDQE, 33 Avenue Jean Jaurès, 94200 Ivry-sur-Seine, France \\ guillaume.darracq@eaudeparis.fr
}

\begin{abstract}
Absorption of hydrophobic Volatile Organic Compounds (VOCs) in multiphase system gas water PolyDiMethylSiloxane (PDMS, i.e. silicone oils) was considered. Absorption experiments were carried out in a countercurrent gas-liquid absorber filled with Raschig rings as packing. Three absorbing liquids, water, PDMS and a mixture of water/PDMS (90/10 v/v) were used to transfer toluene and dimethyl disulfide (DMDS) selected as VOC targets. Moreover, the Equivalent Absorption Capacity (EAC) concept previously developed to characterize the mixtures of water/PDMS was applied to the experimental data obtained at three different gas flow rates (18, 25 and $32 \mathrm{~m}^{3} \mathrm{~h}^{-1}$ ). Experimental measurements showed that absorption efficiencies (E) were low for water (around 2-8\% for toluene and around 12-25\% for DMDS) and higher for PDMS (from $88 \%$ to $98 \%$ according to the operating conditions). For the water/PDMS mixture, it was shown that the PDMS addition increased significantly the absorption of pollutants (E values in the range 25 to $65 \%$ according to the operating conditions). Besides, it was emphasized that the EAC concept describes satisfactorily the absorption behavior of the water/PDMS mixture. Finally, results confirmed that pure PDMS has to be used rather than a (90/10 v/v) water/PDMS mixture for hydrophobic VOC absorption. Using pure PDMS as absorbing liquid (dynamic viscosity of 5 $\mathrm{mPa}$ ), high absorption efficiencies (up to 98\%) were obtained for L'/G' value around 5 (L'/G' corresponding to the ratio between the specific flow of the liquid and the specific flow of the gas). Under such conditions, pressure drops $(\boldsymbol{P})$ in the packed column and overall mass transfer coefficients $\left(\mathrm{K}_{\mathrm{L}} \mathrm{a}\right)$ were around $1000 \mathrm{~Pa} \mathrm{~m}^{-1}\left(\mathrm{G}^{\prime}=1.06 \mathrm{~kg} \mathrm{~m}^{-2} \mathrm{~h}^{-1}\right)$ and $510^{-3} \mathrm{~s}^{-1}$, respectively.
\end{abstract}

Keywords: Multiphase absorption; Mass transfer; Silicone oil; Air pollution; VOC; PDMS. 


\section{Nomenclature}
A: absorption factor (dimensionless)
C: VOC concentration $\left(\mathrm{g} \mathrm{m}^{-3}\right)$
$\mathrm{D}$ : column diameter $(\mathrm{m})$
E: efficiency (dimensionless)
$\mathrm{G}$ : molar flow of the gas $\left(\mathrm{mol} \mathrm{s}^{-1}\right)$
$\mathrm{G}^{\prime}$ : specific flow of the gas $\left(\mathrm{kg} \mathrm{m}^{-2} \mathrm{~s}^{-1}\right)$
$\mathrm{H}$ : partition coefficient $\left(\mathrm{Pa} \mathrm{m}^{3} \mathrm{~mol}^{-1}\right)$
$\mathrm{K}_{\mathrm{L}} \mathrm{a}$ : overall mass transfer coefficients $\left(\mathrm{s}^{-1}\right)$
$\mathrm{L}$ : molar flow of the liquid $\left(\mathrm{mol} \mathrm{s}^{-1}\right)$
L': specific flow of the liquid $\left(\mathrm{kg} \mathrm{m}^{-2} \mathrm{~s}^{-1}\right)$
M: molecular weight $\left(\mathrm{kg} \mathrm{mol}^{-1}\right)$
$\mathrm{N}$ : Number of stages (dimensionless)
$\mathrm{m}$ : partition coefficient (dimensionless)
$\mathrm{R}$ : ideal gas constant $\left(8.314 \mathrm{~J} \mathrm{~mol}^{-1} \mathrm{~K}^{-1}\right)$
$\mathrm{T}$ : temperature $(\mathrm{K})$
Q: flow rate $\left(\mathrm{m}^{3} \mathrm{~s}^{-1}\right)$
$\mathrm{V}$ : packing volume $\left(\mathrm{m}^{3}\right)$
$\mathrm{Z}$ : packing height $(\mathrm{m})$

Greek letters

$\Delta$ : pressure drop $(\mathrm{Pa})$

$\phi$ PDMS volume fraction (dimensionless)

$\eta$ dynamic viscosity (Pa s)

$\rho$ density $\left(\mathrm{kg} \mathrm{m}^{-3}\right)$

\section{Superscripts \\ *: equilibrium}

Subscripts

G: gas

L: liquid

in: inlet

out: outlet

Mix: relative to the mixture

Water: relative to the aqueous phase

PDMS: relative to the silicone oil phase 


\section{Introduction}

The removal of volatile organic compounds (VOCs) can be achieved using bioscrubbers. However, some VOCs are scarcely soluble in water leading to mass transfer limitations. In response to the low solubility of hydrophobic pollutants, a Non Aqueous Phase Liquid (NAPL) can be added to water in order to improve the mass transfer of pollutants from the gas phase to the liquid phase [1-3]. The NAPL acts therefore as a reservoir of pollutants. To date, PolyDiMethylSiloxane (PDMS, i.e. silicone oils) have been identified as the best organic solvents for the biological treatment of hydrophobic VOCs [4]. The biodegradation of VOCs is then obtained using a process in three steps: (i) the "absorption step": a gas/liquid contactor dedicated to the VOCs absorption from the gaseous phase to the liquid phase (PDMS or PDMS/water mixture); (ii) "the biodegradation step": a Two Phase Partitioning Bioreactor (TPPB) allowing the biodegradation of VOCs contained in the PDMS. In this step, VOCs are gradually transferred from the PDMS to the water phase containing microorganisms. Hence, the biodegradation of hydrophobic pollutants allow to "regenerate" the PDMS; (iii) "separation step": once regenerated, the PDMS is separated from water and recycled without microorganisms towards the absorber (Fig. 1). The aqueous phase containing the biomass is partially recycled in the TPPB.

The present study is devoted to the absorption step. The mass transfer in such multiphase system (gas/PDMS/water) can be performed in a countercurrent gas-liquid absorber whose design procedure is well described in the literature $[5,6]$. However, when the liquid phase consists of a mixture of an aqueous phase and a non-aqueous liquid phase, the physicochemical properties of the mixture have to be sufficiently known to enable the design to be carried out. The major 
problem for the design of such a multiphase absorber depends directly on the knowledge of the equilibrium solubility of the VOCs between the gas phase and the water/PDMS mixture. To solve this issue, an Equivalent Absorption Capacity (EAC) concept has been developed for reactor design [7-9]. According to this concept, the absorption capacity of any water/PDMS mixture is equivalent to that of a pseudo-homogeneous phase whose physical properties (VOC partition coefficient $\mathrm{H}_{\text {mix }}$, molecular weight $\mathrm{M}_{\text {mix }}$ and density pnix $_{\text {) }}$ can be calculated whatever the PDMS volume fraction in the mixture (థ). To date, the EAC concept, developed from batch experiments [9], has been used to predict the influence of the silicone volume fraction on the physical absorption of different VOCs in a countercurrent gas-liquid absorber [8]. However, these predictive results need to be validated for continuous conditions. The aim of this study was therefore to experimentally apply the concept to data obtained in a countercurrent gas-liquid packed absorber contacting a gas flow and a (90/10 v/v) water/PDMS mixture. Three gas flow rates loaded with toluene and dimethyl disulfide (DMDS) selected as VOC targets were used. Moreover, results from the EAC concept were critically compared to results obtained from the classical procedure calculation based on linear change in VOC partition coefficient with PDMS volume fraction. 


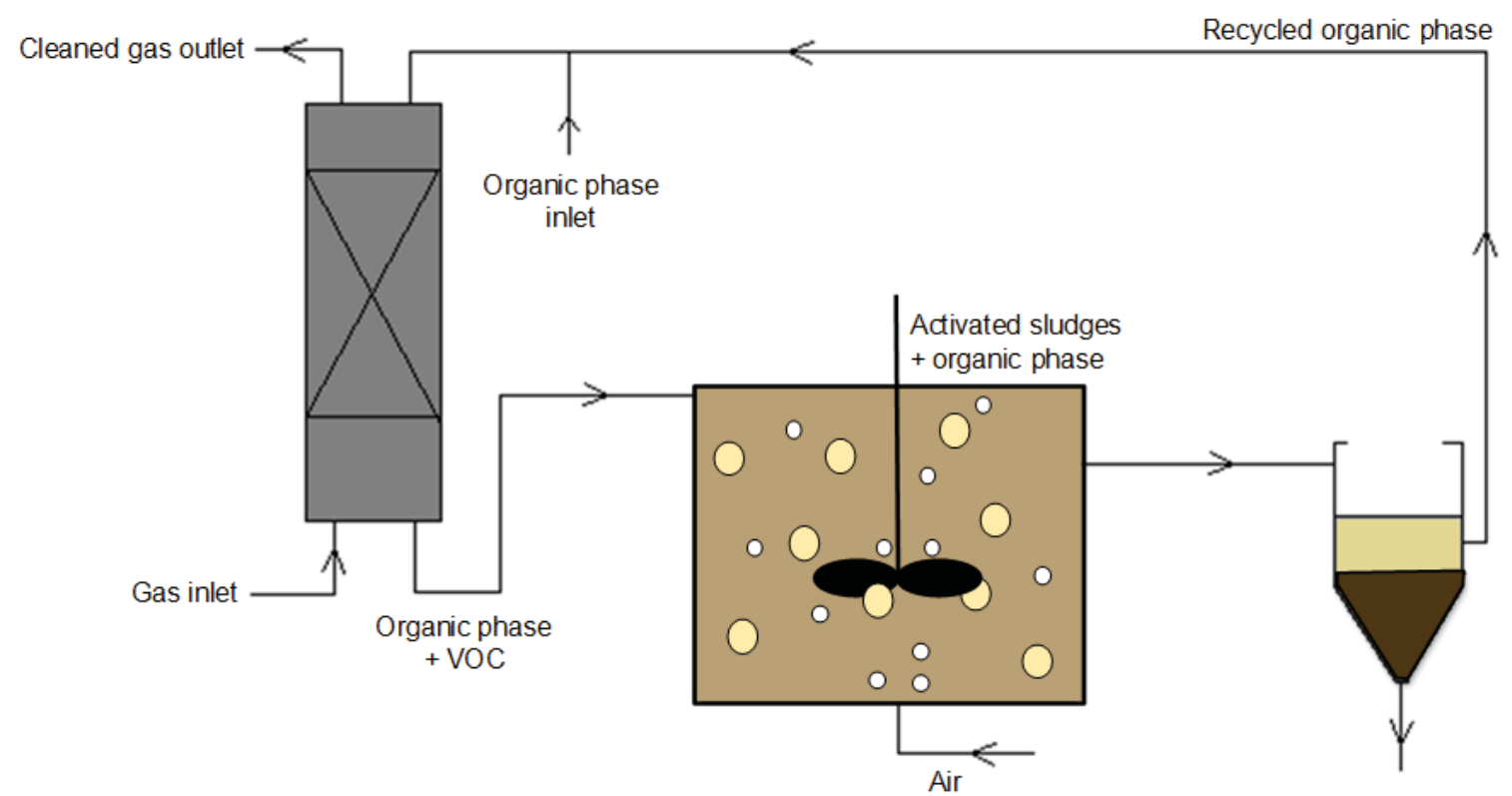

\section{Absorption Biodegradation}

Separation

Fig. 1. Absorption-biodegradation process with organic phase regeneration for hydrophobic VOCs treatment.

\section{Equivalent Absorption Capacity (EAC) concept}

This empirical concept is based on experimental mass transfer measurements carried out in a batch reactor between air and various water/PDMS mixtures. The experimental procedure described in Dumont et al. [9] demonstrated that the absorption capacity of any water/PDMS mixture is equivalent to that of a pseudo-homogeneous phase whose physical properties (molecular weight $\mathrm{M}_{\text {mix }}$ and density pmix) can be expressed using the following equations:

$$
\begin{aligned}
& M_{\text {mix }}=(1-\phi) M_{\text {water }} \frac{H_{\text {mix }}}{H_{\text {water }}} \frac{\rho_{\text {mix }}}{\rho_{\text {water }}}+\phi M_{P D M S} \frac{H_{\text {mix }}}{H_{P D M S}} \frac{\rho_{\text {mix }}}{\rho_{P D M S}} \\
& \rho_{\text {mix }}=(1-\phi) \rho_{\text {water }} \frac{H_{\text {mix }}}{H_{\text {water }}}+\phi \rho_{P D M S} \frac{H_{\text {mix }}}{H_{P D M S}}
\end{aligned}
$$


With:

$\frac{1}{H_{\text {mix }}}=\frac{(1-\phi)}{H_{\text {water }}}+\frac{\phi}{H_{P D M S}}$

The VOC partition coefficient $\left(\mathrm{H}_{\text {mix }}\right)$ between air and a water/PDMS mixture is expressed as a function of the VOC partition coefficients for air/water and air/PDMS, respectively, and as a function of the silicone volume fraction in the mixture ( $\phi$. It can be observed that the mathematical expressions of $\mathrm{M}_{\text {mix }}$ and $\beta_{\text {mix }}$ depend on the physical properties of water and PDMS, balanced according to their proportions in the mixture (i.e. (1- $\phi) M_{w a t e r}$ and $\phi M_{\text {PDMS }} ;(1-\phi) \rho_{\text {water }}$ and $\phi_{\mathrm{DMS}}$, respectively). Moreover, the physical properties of water and PDMS should also be balanced using the non-dimensional ratios $\mathrm{H}_{\text {mix }} / \mathrm{H}_{\text {water }}$ and $\mathrm{H}_{\text {mix }} / \mathrm{H}_{\text {PDMS. The importance to take }}$ into account these correction factors on the actual absorption capacity of the mixture was highlighted in Dumont et al. [7]. These correction factors allow to moderate the importance of the mole number of water, which has a weak absorption capacity, and to actually consider the importance of the mole number of PDMS, which has a large absorption capacity. From a mass transfer point of view, the EAC concept presents the advantage of showing that a heterogeneous water/PDMS mixture has an absorption capacity equivalent to that of a pseudo-homogeneous phase [8].

\section{Material and methods}

\subsection{Chemical products}

Silicone oil (PDMS, Rhodorsil® fluids 47V5) with a viscosity of $510^{-3} \mathrm{~Pa}$ s was purchased from the BlueStar Company, France. The molecular weight and the density of this PDMS are $740 \mathrm{~g}$ $\mathrm{mol}^{-1}$ and $910 \mathrm{~kg} \mathrm{~m}^{-3}$, respectively. 
Toluene $\left(\mathrm{C}_{7} \mathrm{H}_{8}\right.$; CAS number: 108-88-3; purity $\geq 99.5 \%$; Sigma Aldrich) and dimethyldisulphide $\left(\mathrm{CH}_{3}-\mathrm{S}-\mathrm{S}-\mathrm{CH}_{3}\right.$; CAS number: 624-92-0; purity $\geq 98 \%$; Sigma Aldrich) were chosen as target pollutants due to their slight solubility in water. Table 1 summarizes the physical data of the selected pollutants. Partition coefficients for PDMS were experimentally measured through a static headspace method [4], and partition coefficients for water (i.e. Henry's constants) are from literature data $[10,11]$.

Table 1. Some physical data of the selected pollutants $(\mathrm{T}=298 \mathrm{~K})$.

\begin{tabular}{ccc}
\hline & Toluene & DMDS \\
\hline Molecular weight $\left(\mathrm{g} \mathrm{mol}^{-1}\right)$ & 92.1 & 94.2 \\
Density $\left(\mathrm{kg} \mathrm{m}^{-3}\right)$ & 870 & 1046 \\
Partition coefficient PDMS $\left(\mathrm{Pa} \mathrm{m}^{3} \mathrm{~mol}^{-1}\right)$ & 2.7 & 3.4 \\
Partition coefficient water $\left(\mathrm{Pa} \mathrm{m}^{3} \mathrm{~mol}^{-1}\right)$ & 680 & 111.9 \\
\hline
\end{tabular}

\subsection{Experimental}

VOC absorption was studied in a packed gas-liquid contactor (inside diameter $0.12 \mathrm{~m}$ ) filled with $1 / 2$ inch glass Raschig rings (hydraulic diameter $1.0610^{-2} \mathrm{~m}$; surface area $310 \mathrm{~m}^{2}$; porosity 0.82 ). The packing (height $1.0 \mathrm{~m}$; volume $11.3 \mathrm{~L}$ ) was held in place top and bottom by grids and the column was topped with a bespoke droplet collector. The polluted air was generated by injecting liquid VOC in an air stream by means of a syringe dispenser (Fig. 2). Using this system, inlet concentrations were $60 \pm 7 \mathrm{mg} \mathrm{m}^{-3}$ and $92 \pm 15 \mathrm{mg} \mathrm{m}^{-3}$ for toluene and DMDS, respectively. The polluted air was then introduced into the bottom of the column and the liquid was flowed counter-currently. The air flow was regulated by means of a membrane valve placed after the fan and measured by a rotameter (GF Type SK 20 CH-8201 Schaffhausen Switzerland). The column was fed with liquid by means of a centrifugal pump (Iwaki MD100, Iwaki America Inc.) and the 
liquid flow rates were regulated by means of a valve and measured by a rotameter (GF type SK 11 CH-8201 Schaffhausen Switzerland).

Studies were carried out for three gas flow rates (around 18, 25 and $32 \mathrm{~m}^{3} \mathrm{~h}^{-1}$, respectively) at a constant gas temperature $(\mathrm{T}=298 \mathrm{~K})$ controlled by means of a thermal exchanger. For each gas flow rate, VOC absorption was studied using three liquid solutions, i.e. (i) water, (ii) PDMS and (iii) a $(90 / 10-v / v)$ water/PDMS mixture $(\phi=0.1)$. Mass transfer efficiency was determined from inlet and outlet VOC concentration measurements using a Flame-Ionization Detector FID (JUM 109 L THC Analyzer) calibrated from standards. Pressure drops were measured using vertical Ushaped tube filled with water.

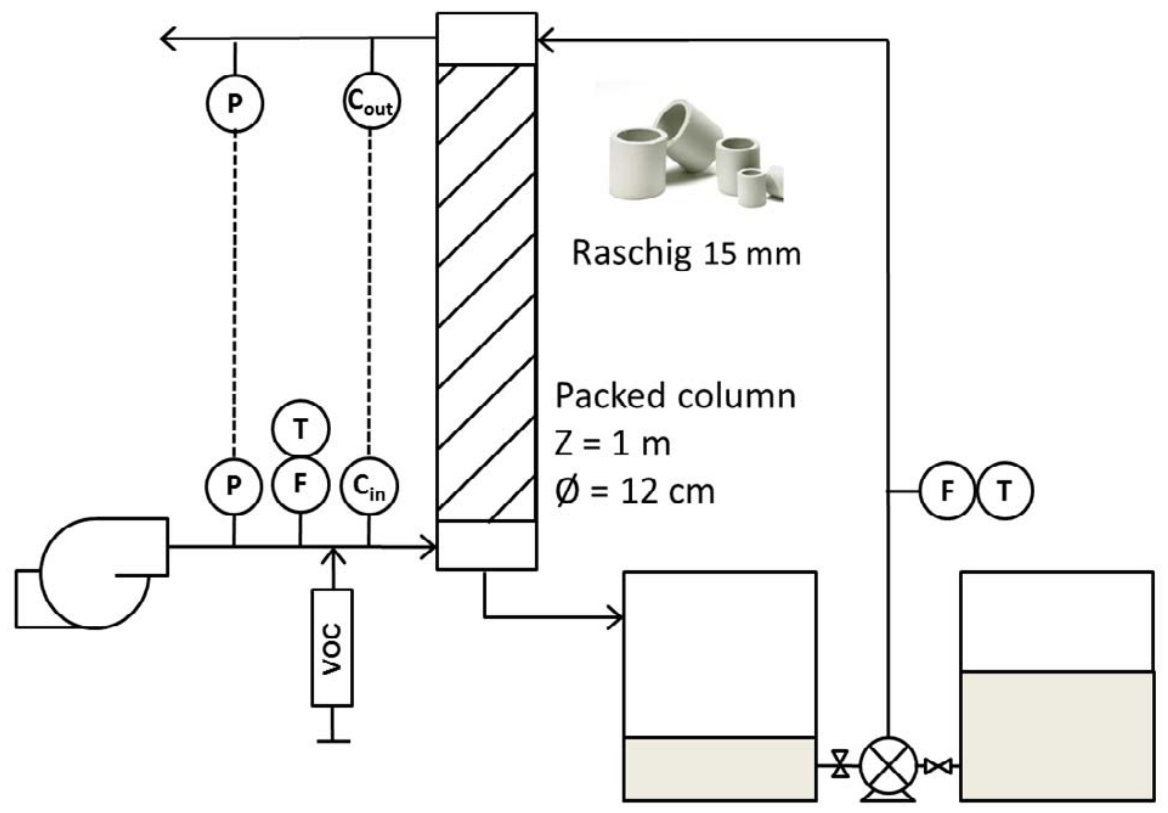

Fig. 2. Experimental set-up for VOCs absorption.

\subsection{Calculation procedure}

The absorption performances were experimentally determined in terms of VOC removal efficiency: 
$E=100 \frac{\left(C_{\text {Gin }}-C_{\text {Gout }}\right)}{C_{\text {Gin }}}$

In an absorption column treating diluted gas, the experimental efficiencies can be described using the Kremser formula [5]:

$E=\frac{A^{N+1}+A}{A^{N+1}+1}$

Where $\mathrm{A}$ is the absorption factor and $\mathrm{N}$ the number of stages.

$A=\frac{L}{m G}$

In Eq. (6), $\mathrm{m}$ is the dimensionless VOC partition coefficient between gas and liquid phases. The relation between $\mathrm{m}$ and $\mathrm{H}$ is given by the following equation:

$m=H\left(\frac{1}{R T}\right)\left(\frac{M_{G} \rho_{L}}{M_{L} \rho_{G}}\right)$

Using Eqs. (6-7), the calculation of the absorption factor is evident for water $(\phi=0)$ and for $\operatorname{PDMS}(\phi=1)$. However, it is more difficult for the water/PDMS mixture $(\phi=0.1)$ since the liquid mole flow rate, the molecular weight and the density of the gas and liquid phases have to be determined. Using the Equivalent Absorption Concept, i.e. assuming that a water/PDMS oil mixture has an absorption capacity equivalent to that of a pseudo-homogeneous liquid phase, the liquid mole flow rate is:

$L_{\text {mix }}=Q_{L} \frac{\rho_{\text {mix }}}{M_{\text {mix }}}$

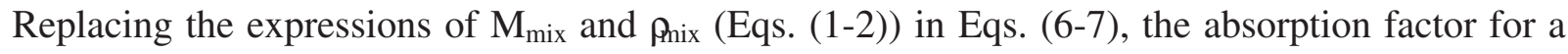
water/PDMS mixture can be expressed as [8]: 
$A=\frac{Q_{L}}{Q_{G}} \frac{R T}{H_{\operatorname{mix}}}$

An alternative form of the absorption factor can be given by replacing the expression of $\mathrm{H}_{\text {mix }}$ (Eq.

(1)) in Eq. (9):

$A=\frac{Q_{L}}{Q_{G}} R T\left(\frac{1}{H_{P D M S}}-\frac{1}{H_{\text {water }}}\right) \phi+\frac{Q_{L}}{Q_{G}} R T \frac{1}{H_{\text {water }}}$

The objective of this study is to show that experimental results obtained for a water/PDMS mixture can be analyzed provided that the EAC concept is used to calculate the absorption factor. However, it has to be noted that the absorption factor (Eq. 6) for water/PDMS mixtures can also be calculated using the assumption that the physical properties (partition coefficient, molecular weight and density) follow a linear evolution from water to PDMS. Such linear evolution was occasionally used to model mass transfer in mixtures of water and immiscible solvents [12-14]. According to this "linear model":

$H_{\text {mix }}=(1-\phi) H_{\text {water }}+\phi H_{P D M S}$

$M_{\text {mix }}=(1-\phi) M_{\text {water }}+\phi M_{P D M S}$

$\rho_{\text {mix }}=(1-\phi) \rho_{\text {water }}+\phi \rho_{P D M S}$

The difference between the EAC concept and the "linear model" model clearly appears in Fig. 3 showing $\mathrm{H}_{\text {mix }}$ values as a function of the PDMS volume fraction ( $\phi$. For the water/PDMS mixture used in this study $(\phi=0.1)$, the physical properties of the mixture calculated according to the EAC concept and according to the "linear model" are summarized in Table 2.

For all experiments, the hydrodynamic of the column was characterized on the basis of the overall mass transfer coefficients $\mathrm{K}_{\mathrm{L}}$ a calculated according to the following equations [15]: 


$$
K_{L} a=\frac{Q_{G}}{V} \frac{\left(C_{\text {Gin }}-C_{\text {Gout }}\right)}{\left(\frac{\left(C_{\text {Gout }} / m-C_{\text {Lin }}\right)-\left(C_{\text {Gin }} / m-C_{\text {Gout }}\right)}{\ln \left(\frac{C_{\text {Gout }} / m-C_{\text {Lin }}}{C_{\text {Gin }} / m-C_{\text {Gout }}}\right)}\right)}
$$

Table 2. Physical properties of the water/PDMS mixture $(\phi=0.1)$ calculated using the EAC concept (Eqs. (1-3)) and according to the "linear model" (Eqs. (11-13)).

\begin{tabular}{ccccc}
\hline & \multicolumn{2}{c}{ Toluene } & \multicolumn{2}{c}{ DMDS } \\
\cline { 2 - 5 } $\mathrm{H}_{\text {mix }}\left(\mathrm{Pa} \mathrm{m}^{3} \mathrm{~mol}^{-1}\right)$ & EAC concept & Linear model & EAC concept & Linear model \\
\cline { 2 - 5 } $\mathrm{M}_{\text {mix }}\left(\mathrm{kg} \mathrm{mol}^{-1}\right)$ & 26.1 & 612.3 & 26.7 & 101.1 \\
Pnix $\left._{\text {ng m}}{ }^{-3}\right)$ & 0.717 & 0.090 & 0.597 & 0.090 \\
\hline
\end{tabular}
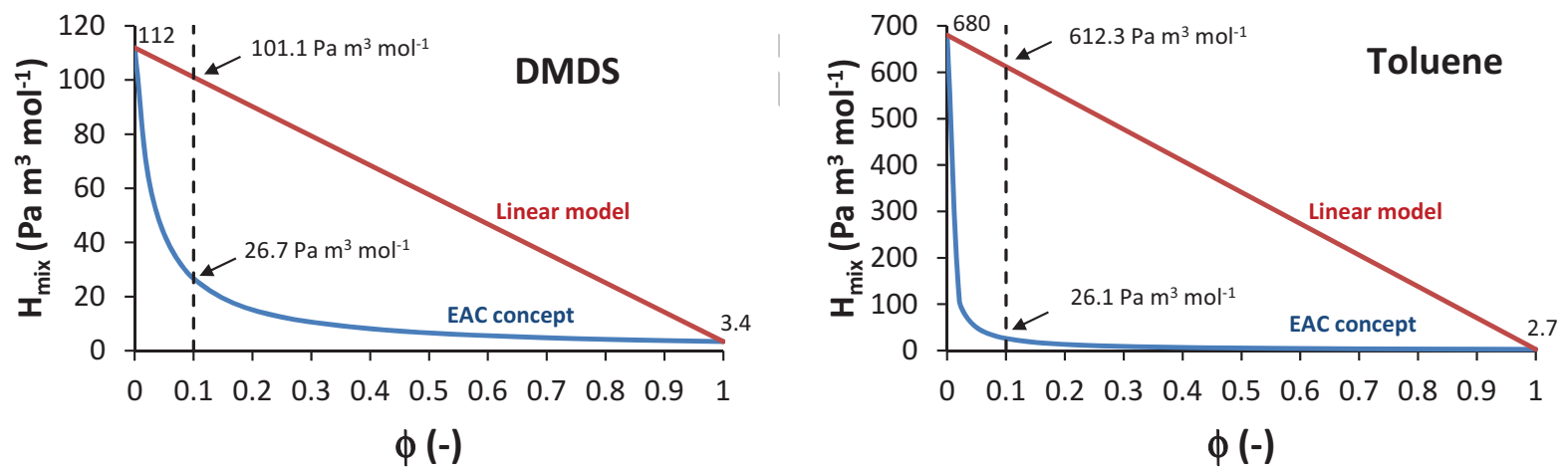

Fig. 3. Partition coefficient values $\left(\mathrm{H}_{\text {mix }}\right)$ for water/PDMS mixtures calculated according to the EAC concept and according to the "linear model" (left: DMDS; right: toluene).

\section{Results and discussion}

\subsection{Determination of the loading zones}

In order to determine the liquid flow rates which could be used for absorption studies, the wet pressure drop measurements were measured for the systems air/water, air/PDMS and air/water/PDMS mixture. The loading zone was then obtained from the analysis of the pressure 
drop curves $\log \Delta$ vs $\log \mathrm{U}_{\mathrm{L}}$ (Fig. 4). Such curve allows to experimentally determine both the loading point and the flooding point for each system studied. Example given at Fig. 4 clearly shows the effects of PDMS volume fraction and liquid flow on the pressure drop in the column. Loading and flooding points are reached at lower liquid flow rates for PDMS, which demonstrated the influence of liquid viscosity (Table 3). According to the results reported in this table, the influence of liquid viscosity is nonetheless less marked at high liquid flow rate $\left(32 \mathrm{~m}^{3}\right.$ $\mathrm{h}^{-1}$ ) than at low liquid flow rate $\left(18 \mathrm{~m}^{3} \mathrm{~h}^{-1}\right)$. Considering the liquid flow rates at the flooding point, the range of liquid flow rates to use for the study of the absorption of hydrophobic VOCs was set according to the absorbing liquid and gas flow rates (Table 4).

Table 3. Loading and flooding liquid flow rates according to gas flow rates and PDMS volume fraction $(\phi)$.

\begin{tabular}{ccccccc}
\hline & \multicolumn{2}{c}{$\mathrm{Q}_{\mathrm{L}}$ loading $\left(\mathrm{m}^{3} \mathrm{~h}^{-1}\right)$} & \multicolumn{3}{c}{$\mathrm{Q}_{\mathrm{L}}$ flooding $\left(\mathrm{m}^{3} \mathrm{~h}^{-1}\right)$} \\
$\mathrm{Q}_{\mathrm{G}}\left(\mathrm{m}^{3} \mathrm{~h}^{-1}\right)$ & $\phi=0$ & $\phi=0.1$ & $\phi=1$ & $\phi=0$ & $\phi=0.1$ & $\phi=1$ \\
\hline 18 & 0.296 & 0.283 & 0.270 & 0.710 & 0.663 & 0.633 \\
25 & 0.219 & 0.200 & 0.187 & 0.438 & 0.317 & 0.296 \\
32 & 0.170 & 0.159 & 0.152 & 0.270 & 0.252 & 0.241 \\
\hline
\end{tabular}

Table 4. Range of liquid flow rates used for absorption studies.

\begin{tabular}{ccccccc}
\hline & \multicolumn{2}{c}{$\phi=0$} & \multicolumn{2}{c}{$\phi=0.1$} & \multicolumn{2}{c}{$\phi=1$} \\
$\mathrm{Q}_{\mathrm{G}}\left(\mathrm{m}^{3} \mathrm{~h}^{-1}\right)$ & $\mathrm{Q}_{\mathrm{L}}\left(\mathrm{m}^{3} \mathrm{~h}^{-1}\right)$ & $\mathrm{L}^{\prime} / \mathrm{G}^{\prime}$ & $\mathrm{Q}_{\mathrm{L}}\left(\mathrm{m}^{3} \mathrm{~h}^{-1}\right)$ & $\mathrm{L}^{\prime} / \mathrm{G}^{\prime}$ & $\mathrm{Q}_{\mathrm{L}}\left(\mathrm{m}^{3} \mathrm{~h}^{-1}\right)$ & $\mathrm{L}^{\prime} / \mathrm{G}^{\prime}$ \\
\hline 18 & $0.26-0.50$ & $10.5-20.5$ & $0.26-0.47$ & $10.8-19.4$ & $0.096-0.33$ & $3.6-12.3$ \\
25 & $0.26-0.42$ & $7.6-12.8$ & $0.24-0.40$ & $7.1-11.5$ & $0.096-0.24$ & $2.6-6.9$ \\
32 & $0.14-0.28$ & $3.3-6.5$ & $0.14-0.25$ & $3.4-5.7$ & $0.096-0.19$ & $2.0-4.4$ \\
\hline
\end{tabular}




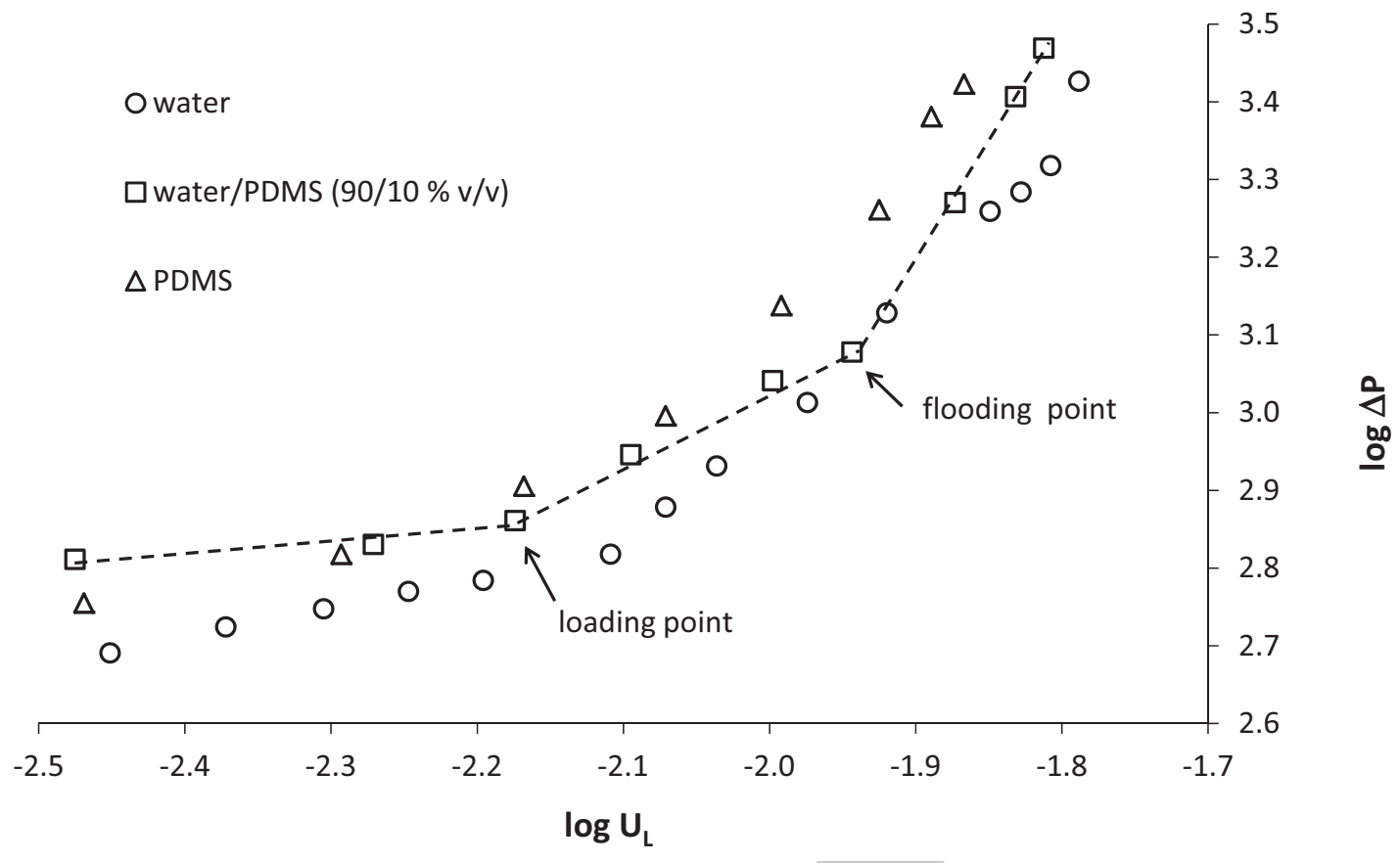

Fig. 4. Example of loading zone determination $\left(\mathrm{Q}_{\mathrm{G}}=25 \mathrm{~m}^{3} \mathrm{~h}^{-1} ; \mathrm{U}_{\mathrm{G}}=0.90 \mathrm{~m} \mathrm{~s}^{-1}\right)$

\subsection{Pressure drops}

Pressure drop measurements were carried out for all absorption experiments. Results obtained for both toluene and DMDS, and for each gas flow rate are presented in Fig. 5. As it can be observed, slight differences can exist between pressure drops recorded for toluene and DMDS experiments under the same operating conditions. Such differences allow to determine the accuracy of pressure drops measurements, which is around 25-30\%. According to Fig. 5, at a constant L'/G' ratio, $\mathbb{P}$ are significantly higher for PDMS than for water, and results obtained for water/PDMS mixture are bounded between both. This expected result is obviously due to the viscosity of the PDMS which is 5 times higher than that of water. For an absorption column packed with Raschig rings, the viscosity of PDMS might have a considerable impact on the energy costs of the process, and another packing could be considered in order to minimize the pressure drops for an industrial application. 


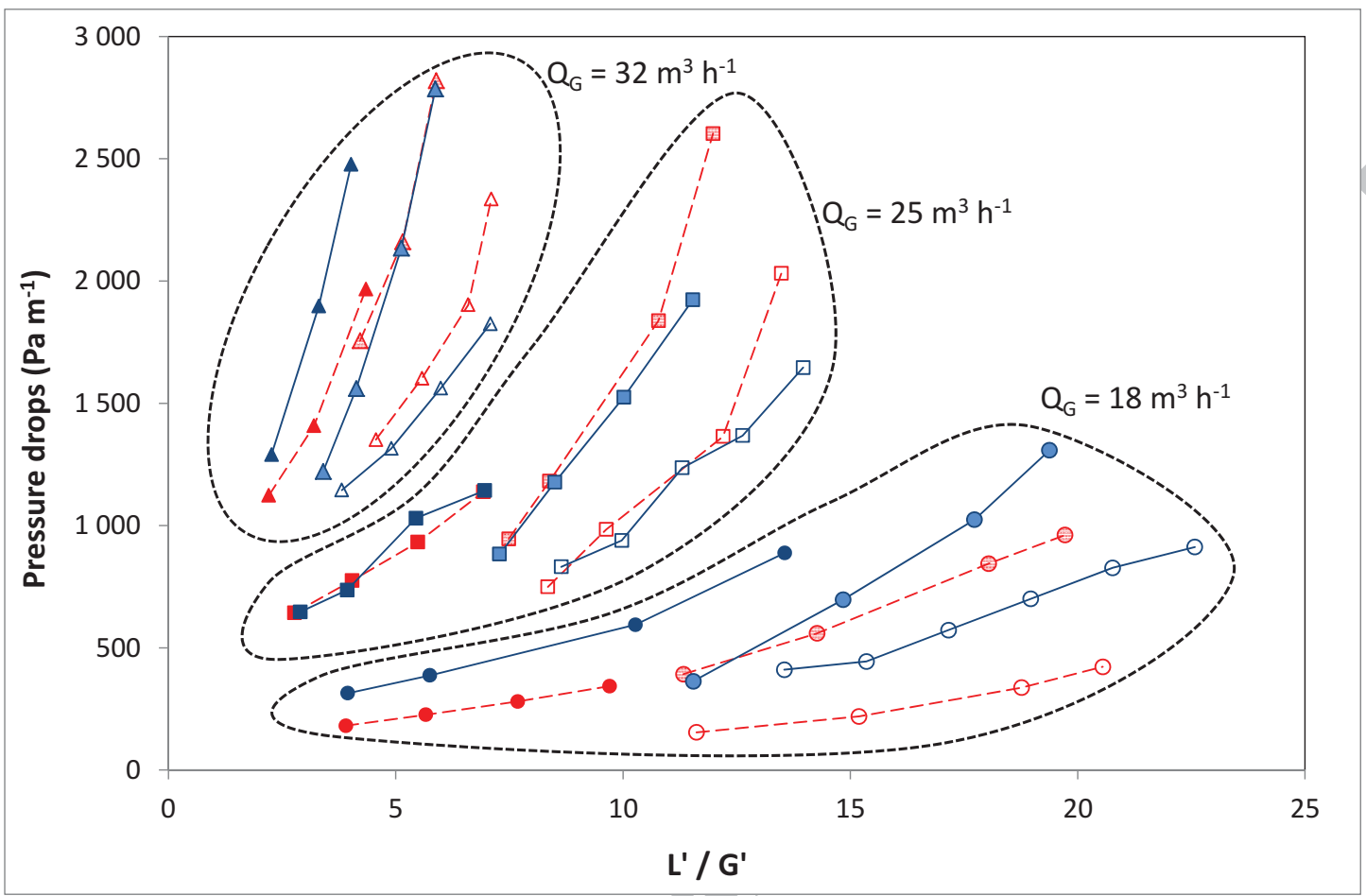

Fig. 5. Pressure drops for each gas flow rate (open symbols: water; shaded symbols: water/PDMS mixture (90/10 v/v); closed symbols: PDMS; continuous lines: toluene experiments; dashed lines:

DMDS experiments).

\subsection{VOC absorption}

Absorption efficiencies for all experiments are presented in Fig. 6. Firstly, it can be observed that pollutant absorption is weak for water used as absorbing liquid $(\phi=0)$. In relation with partition coefficient values $\left(\mathrm{H}=680\right.$ and $111.9 \mathrm{~Pa} \mathrm{~m}^{3} \mathrm{~mol}^{-1}$ for toluene and DMDS, respectively), efficiencies are very low for toluene (around 2-8\%) and slightly higher for DMDS (around 12$25 \%$ ). Secondly, the addition of $10 \%$ PDMS increases significantly the capacity of the column to absorb pollutants, with removal efficiencies ranging from 25 to $65 \%$ according to gas and liquid flow rates. Such finding is mainly due to the significant decrease of the partition coefficient values due to PDMS addition $\left(\mathrm{H}=26.1\right.$ and $26.7 \mathrm{~Pa} \mathrm{~m}^{3} \mathrm{~mol}^{-1}$ for toluene and DMDS, 
respectively). It has to be noted that partition coefficient values for water/PDMS mixture are similar for both pollutants although values for water are very different. This can be explained because the partition coefficient values of pollutants for PDMS are similar, while according to Eq. (3), the partition coefficient of water has no influence on the partition coefficient of mixture for a 10\% PDMS volume fraction (Fig. 3). Thirdly, for PDMS used as absorbing liquid $(\phi=1)$, pollutant absorption efficiencies are ranged from $88 \%$ to $98 \%$ according to the operating conditions. Such expected results, which are similar for toluene and DMDS, are consistent with the low partition coefficient values of pollutants $\left(\mathrm{H}=2.7\right.$ and $3.4 \mathrm{~Pa} \mathrm{~m}^{3} \mathrm{~mol}^{-1}$ for toluene and DMDS, respectively). From Fig. 6, it can be noticed that absorption efficiency is slightly dependent on the L'/G' ratio for bad and good absorbents (water and PDMS respectively). Nonetheless, for pure PDMS, it has to be emphasized that absorption efficiency slightly decreased for L'/G' ratio lesser than 4. Indeed, under such conditions, the liquid flow rate is lower than the loading flow rate (Table 3) and consequently, the amount of PDMS used for absorption is insufficient to keep the packing surface thoroughly wet. Conversely, for the water/PDMS mixture, absorption efficiency is strongly dependent on the L'/G' ratio. In a first approach, one may suppose that VOC absorption in pure absorbing liquids (water or PDMS) would be mainly governed by thermodynamic properties rather than the hydrodynamic of the column, whereas for water/PDMS mixture, hydrodynamic conditions would have a major influence on absorption efficiency. In order to check this assumption, the overall mass transfer coefficients have to be considered. Example of $K_{L}$ a measured for a gas flow rate of $25 \mathrm{~m}^{3} \mathrm{~h}^{-1}$ is presented in (Fig. 7). It can be observed that the increase of viscosity lowers the mass transfer coefficient. For water, and considering all operating conditions, it was measured that $\mathrm{K}_{\mathrm{L}}$ a ranges from $110^{-2}$ to $310^{-2} \mathrm{~s}^{-1}$, which corresponds to the values reported in the literature [15]. For PDMS, $\mathrm{K}_{\mathrm{L}}$ a values range from $210^{-3}$ to $1.210^{-2} \mathrm{~s}^{-1}$ and it has to be noted that the greatest $\mathrm{K}_{\mathrm{L}} \mathrm{a}$ 
value determined for PDMS roughly corresponds to the lowest $\mathrm{K}_{\mathrm{L}}$ a value measured for water. For water/PDMS mixture, $\mathrm{K}_{\mathrm{L}}$ a values are on the whole between water and PDMS values. To sum up, it can be emphasized for pure absorbing liquids, that the concentration driving force, low for water and high for PDMS, controls the mass transfer in the case of water, whereas it is not the limiting factor for PDMS. Moreover, for water/PDMS mixtures, both the concentration driving force and the $\mathrm{K}_{\mathrm{L}} \mathrm{a}$ influence the mass transfer. Such finding can be highlighted by the determination of the absorption factor as explained below.

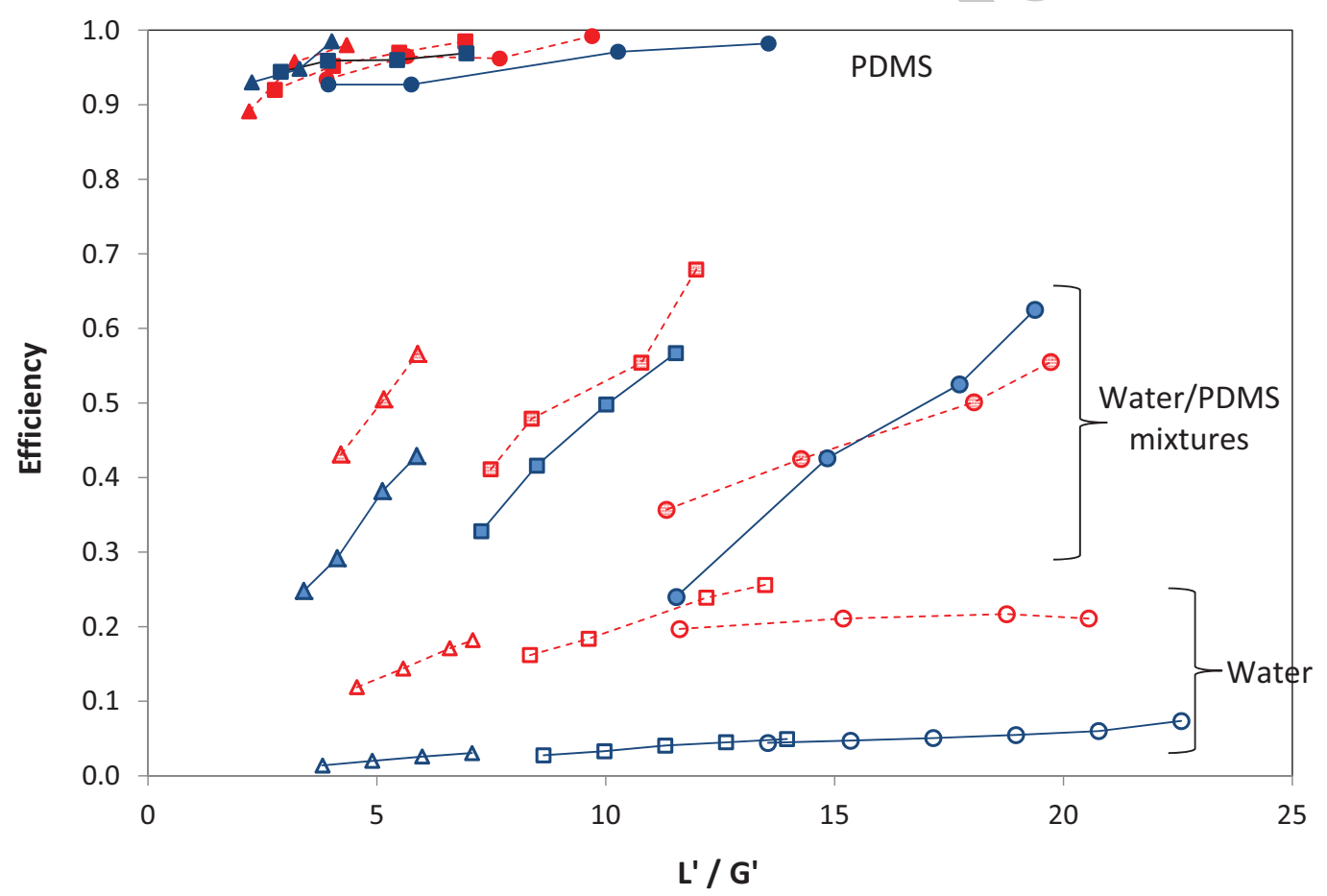

Fig. 6. Absorption efficiency for all experiments (open symbols: water; shaded symbols: water/PDMS mixture (90/10 v/v); closed symbols: PDMS; continuous lines: toluene experiments; dashed lines: DMDS experiments; circle: $18 \mathrm{~m}^{3} \mathrm{~h}^{-1}$; square: $25 \mathrm{~m}^{3} \mathrm{~h}^{-1}$; triangle: $32 \mathrm{~m}^{3} \mathrm{~h}^{-1}$ ). 


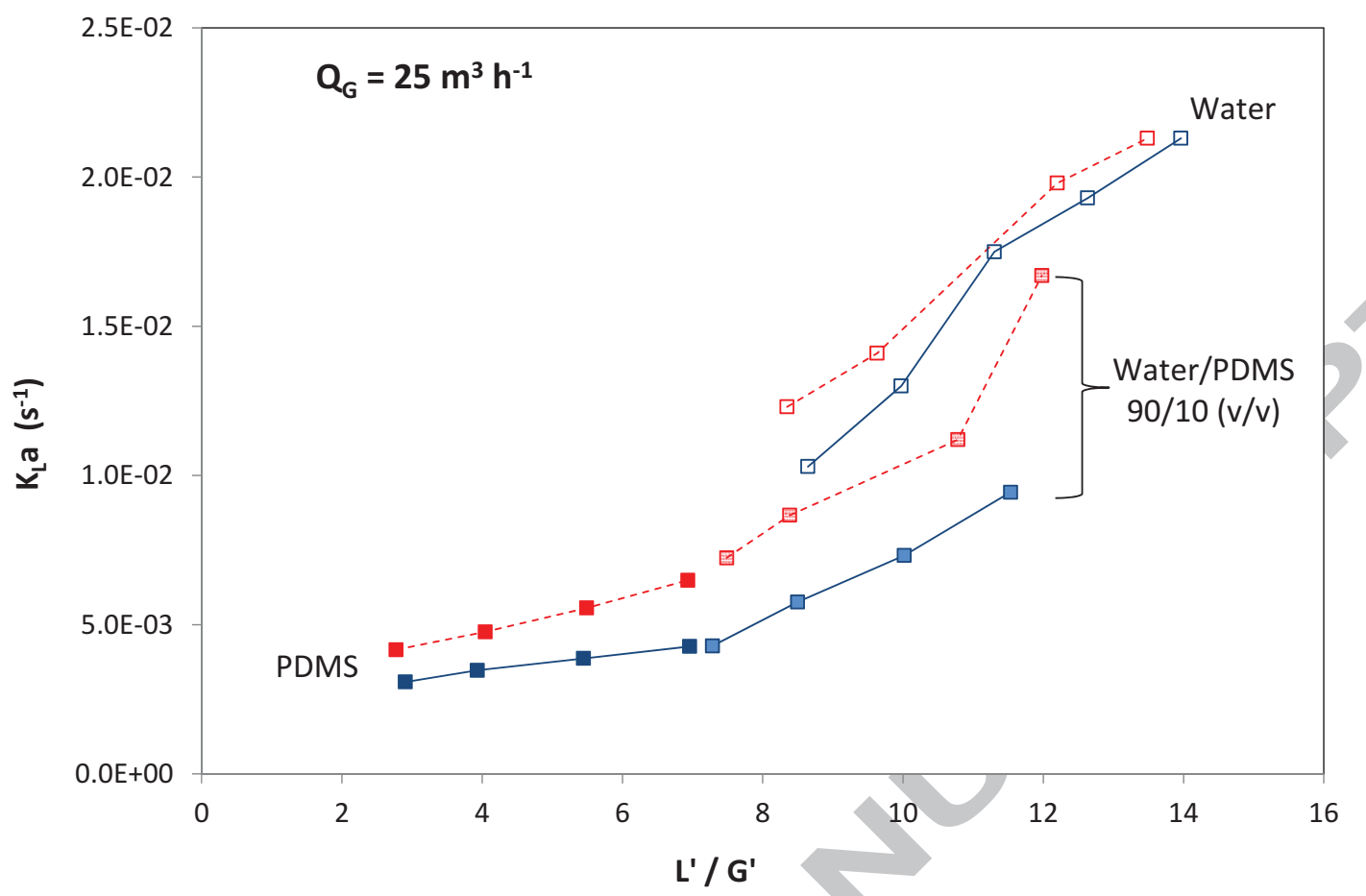

Fig. 7. $\mathrm{K}_{\mathrm{L}}$ a values vs L'/G' ratio according to the absorbing liquid (open symbols: water; shaded symbols: water/PDMS mixture (90/10 v/v); closed symbols: PDMS; continuous lines: toluene experiments; dashed lines: DMDS experiments).

The experimental absorption efficiencies are compared with efficiencies calculated using the Kremser formula. Figs. 8-10 show results obtained for the three gas flow rates and for the target pollutants, DMDS and toluene. For water, values of the absorption factor are close to 0 , in relation to the high partition coefficient values (Table 1). Conversely, for PDMS used as absorbing liquid $(\phi=1)$, the low partition coefficient values of the pollutants allow to obtain absorption factors higher than 2, which corresponds to satisfactory conditions for an effective absorption. For this absorbing liquid, the comparison between experimental results and Kremser formula indicates that the packed bed in the absorption column is equivalent to two theoretical stages at a gas flow rate of $25 \mathrm{~m}^{3} \mathrm{~h}^{-1}$. In other words, it can be concluded that the height equivalent to a theoretical plate (HETP) is $0.5 \mathrm{~m}$ for these operating conditions, which is in agreement with the values reported in the literature for a randomly packed laboratory-scale 
absorption column [16]. As it can be observed in Figs. 8-10, the number of stages logically varies according to the gas flow rate studied because a greater gas flow increases the mass transfer in the packing bed. This trend is clearly evidenced in Fig. 11 giving the change in $\mathrm{K}_{\mathrm{L}} \mathrm{a}$ vs gas flow rates, even if the change in $\mathrm{K}_{\mathrm{L}}$ a values is moderated owing to the liquid viscosity. According to this figure, it has to be noted that $\mathrm{K}_{\mathrm{L}} \mathrm{a}$ values for toluene were systematically lower than $\mathrm{K}_{\mathrm{L}} \mathrm{a}$ values for DMDS (around 30\%). Since the operating conditions were the same for both pollutants, and assuming that mass transfer can be satisfactorily described by the double film theory, it can be concluded that the difference would be due to a difference between the diffusion coefficient values of VOCs rather than difference between gas/liquid superficial areas or boundary layer thicknesses. An attempt of experimental measurement of the diffusion coefficient values of DMDS and toluene in the PDMS used was carried out [4]. According to this study, diffusion coefficient values were $5.6510^{-10}$ and $8.7210^{-11} \mathrm{~m}^{2} \mathrm{~s}^{-1}$ for toluene and DMDS, respectively. Such results are not in agreement with $\mathrm{K}_{\mathrm{L}}$ a values reported in Fig. 11 suggesting that DMDS diffusion coefficient should be higher than toluene diffusion coefficient. For comparison, [15] reported a diffusion coefficient of toluene in a viscous liquid absorbent (DEHA, i.e. di(2-ethylhexyl) adipate; $\eta=12.510^{-3}$ Pa.s at $293 \mathrm{~K}$ ) of $8.6510^{-10} \mathrm{~m}^{2} \mathrm{~s}^{-1}$. Such a value could be consistent with the diffusion coefficient of toluene in PDMS. Unfortunately, DMDS and toluene diffusion coefficient values in various PDMS are not available in the literature and the accurate experimental determination of this physical property in viscous fluid remains always a challenge. As a result, we have to remain cautious about the interpretation of the difference between $\mathrm{K}_{\mathrm{L}} \mathrm{a}$ measured for both pollutants. In the last analysis, this difference could give information about the accuracy of the experimental measurement of the mass transfer between air and a viscous fluid in a randomly packed tower. 


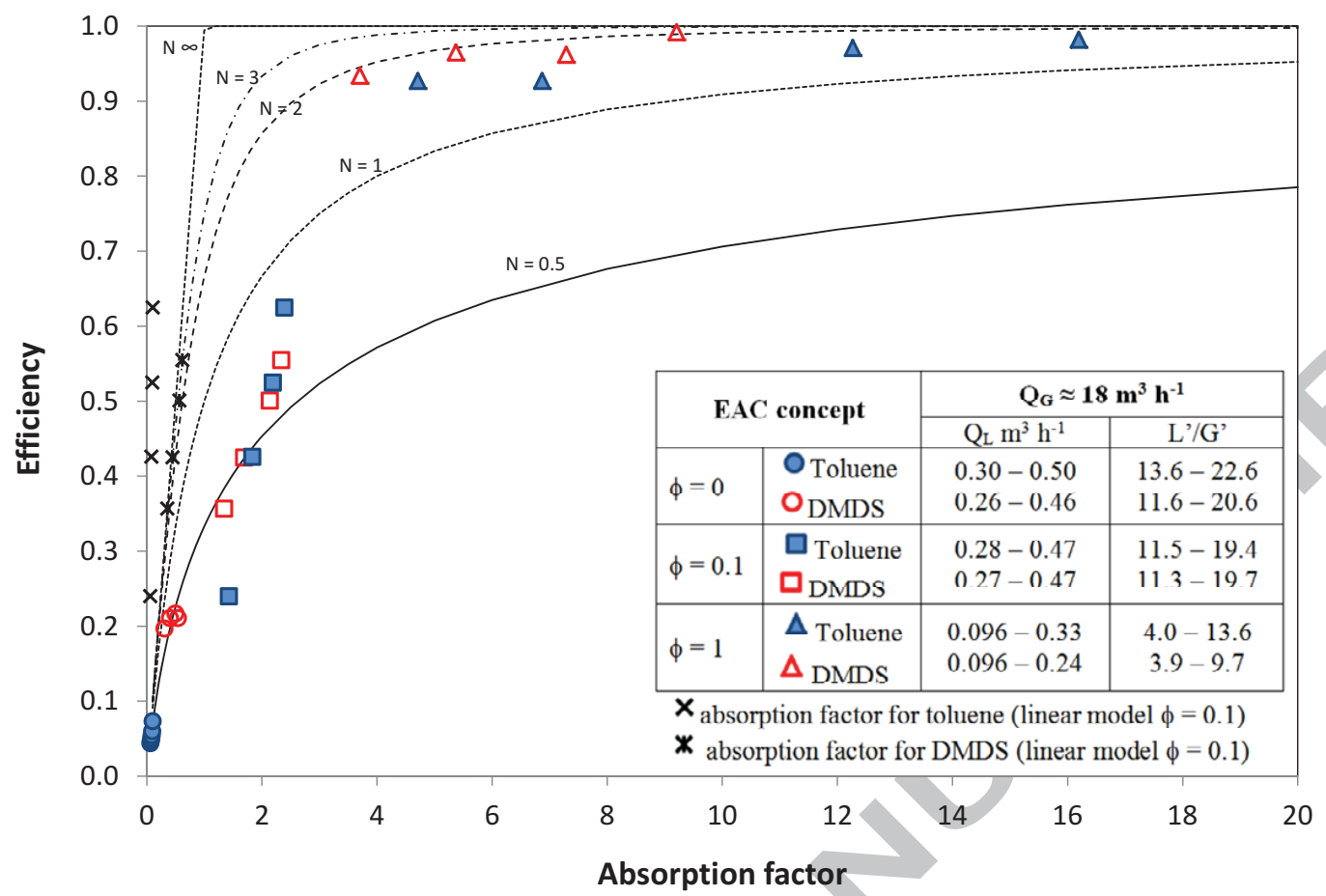

Fig. 8. Absorption efficiency vs absorption factor for gas flow rate $\mathrm{Q}_{\mathrm{G}} \approx 18 \mathrm{~m}^{3} \mathrm{~h}^{-1}$ $\mathrm{U}_{\mathrm{G}} \approx 0.66 \mathrm{~m} \mathrm{~s}^{-1} ; \mathrm{G}^{\prime} \approx 0.78 \mathrm{~kg} \mathrm{~m}^{-2} \mathrm{~s}^{-1}$ ).

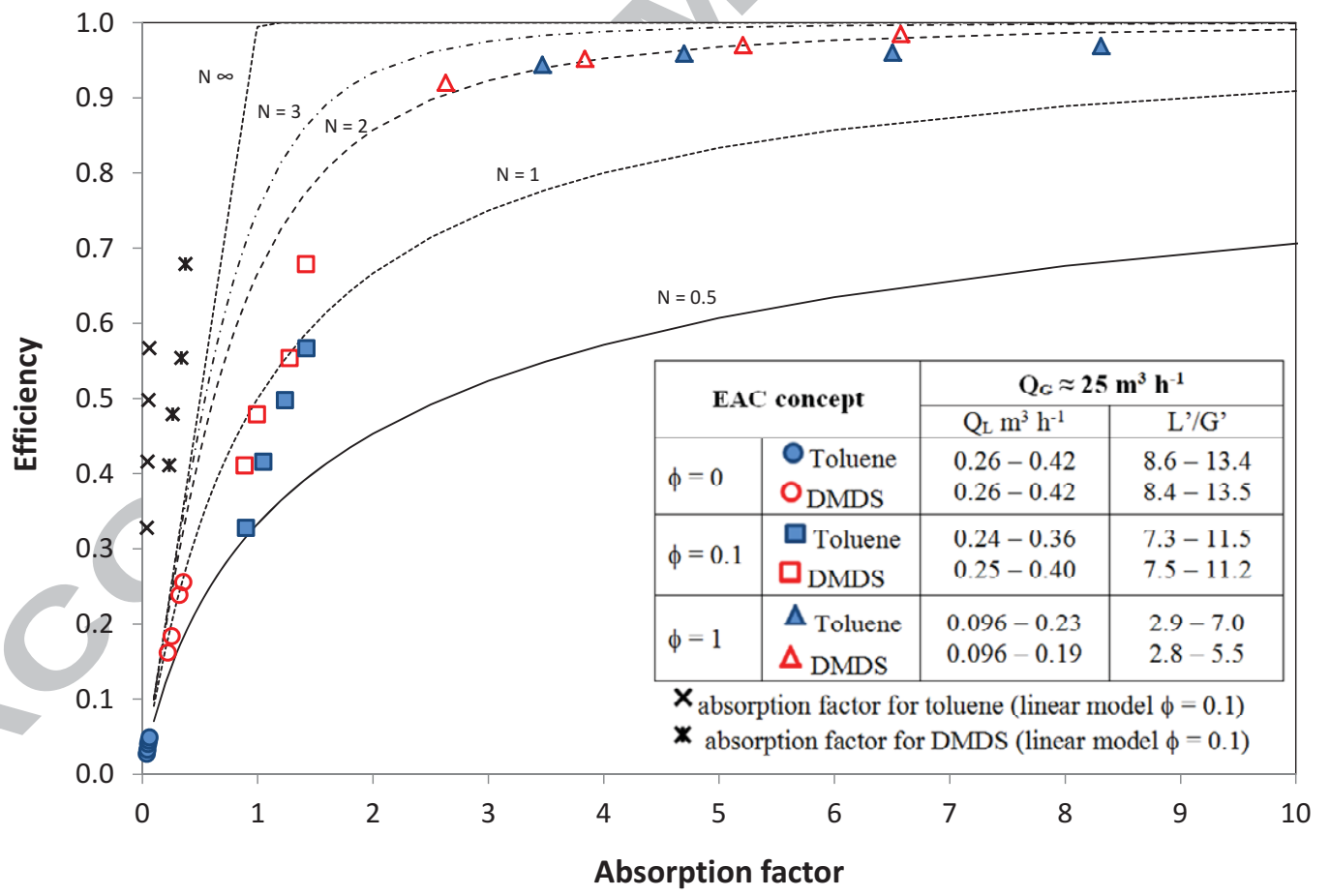

Fig. 9. Absorption efficiency vs absorption factor for gas flow rate $\mathrm{Q}_{\mathrm{G}} \approx 25 \mathrm{~m}^{3} \mathrm{~h}^{-1}$ $\left(\mathrm{U}_{\mathrm{G}} \approx 0.90 \mathrm{~m} \mathrm{~s}^{-1} ; \mathrm{G}^{\prime} \approx 1.06 \mathrm{~kg} \mathrm{~m}^{-2} \mathrm{~s}^{-1}\right)$. 


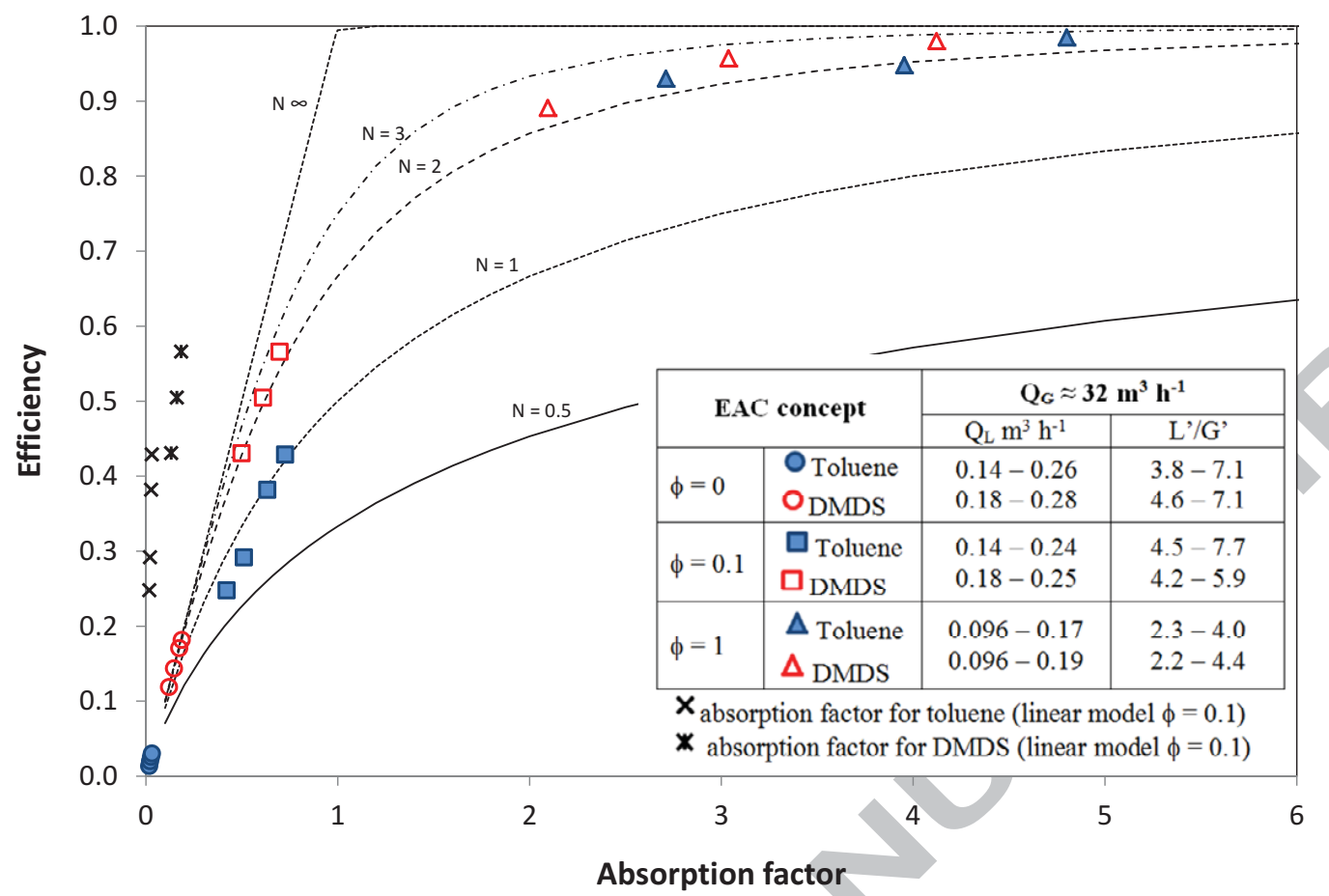

Fig. 10. Absorption efficiency vs absorption factor for gas flow rate $\mathrm{Q}_{\mathrm{G}} \approx 32 \mathrm{~m}^{3} \mathrm{~h}^{-1}$ $\left(\mathrm{U}_{\mathrm{G}} \approx 1.10 \mathrm{~m} \mathrm{~s}^{-1} ; \mathrm{G}^{\prime} \approx 1.30 \mathrm{~kg} \mathrm{~m}^{-2} \mathrm{~s}^{-1}\right)$.

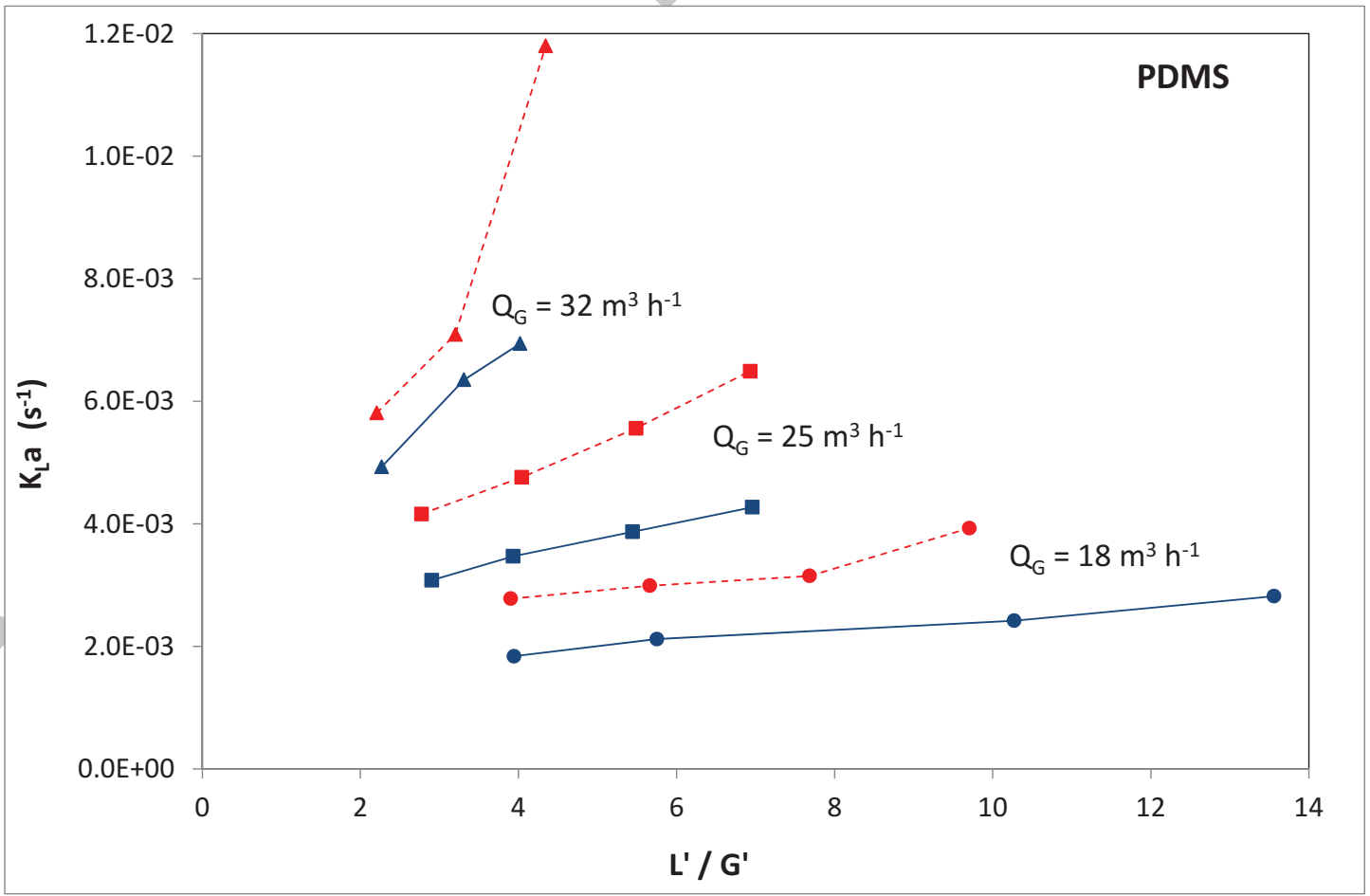

Fig. 11. Change in $\mathrm{K}_{\mathrm{L}}$ a vs gas flow rate for PDMS as absorbing liquid (continuous lines: toluene experiments; dashed lines: DMDS experiments). 
For the water/PDMS mixture $(\phi=0.1)$, the absorption factor (Eq. (6)) is calculated according to the EAC concept (Eq. (9)), and according to the "linear model" (Eqs. (6-8, 11-13)). Figs. 8-10 demonstrate that the procedure calculation based on linear change in VOC partition coefficient with PDMS volume fraction cannot be used for mixtures of immiscible liquids. Indeed, the calculated absorption factor values are lower than the absorption factor corresponding to an infinite number of ideal stages, which is obviously not possible. This result is due to the use of wrong values of partition coefficients which are higher than the actual values experimentally measured and modeled using Eq. (3) (Table 2). Conversely, experimental results highlight that the EAC concept describes satisfactorily the absorption behavior of the water/PDMS mixture. According to Figs. 8-10, i.e. whatever the gas flow rate, the absorption efficiency strongly depends on change in absorption factor value. This information is consistent with that reported in Fig. 6 highlighting the strong dependence of the absorption efficiency versus L'/G' ratio. Given that the partition coefficient values are constant for all experiments carried out with water/PDMS mixture $\left(\mathrm{H}=26.1\right.$ and $26.7 \mathrm{~Pa} \mathrm{~m}^{3} \mathrm{~mol}^{-1}$ for toluene and DMDS, respectively), such finding signify that the absorption efficiency mainly depends on the amount of PDMS flowing in the column, whatever the amount of water, as it will be shown below. Nonetheless, it has to be noticed that the absorption efficiencies measured for toluene for the gas flow rate $Q_{G}=32 \mathrm{~m}^{3} \mathrm{~h}^{-1}$ $(25 \% \leq \mathrm{E} \leq 43 \%)$ were significantly lower than those determined for DMDS in similar conditions (Fig. 10). Such a result can be explained by the hydrodynamic of the column as shown in Fig. 12 giving the $\mathrm{K}_{\mathrm{L}} \mathrm{a}$ values for the different gas flow rates. As observed in this figure, for $\mathrm{Q}_{\mathrm{G}}=32 \mathrm{~m}^{3}$ $\mathrm{h}^{-1}, \mathrm{~K}_{\mathrm{L}}$ a for toluene are four-fold lower than for DMDS, which cannot be explained by a possible inaccuracy of the experimental measurement. The most likely explanation is that the flow of a mixture of immiscible liquids having different densities in the column could not be homogeneous. Consequently, hydrodynamic characterization could vary significantly from one 
experiment to another. Obviously, such an observation is not in favor of the use of a water/PDMS mixture at industrial scale.

To highlight that the absorption efficiency of a water/PDMS mixture mainly depends on the amount of PDMS in the column, whatever the amount of water, Fig. 13 presents the absorption efficiency versus the PDMS amount flowing in the column $\left(\mathrm{Q}_{\mathrm{PDMS}}=\phi \mathrm{Q}_{\mathrm{L}}\right)$. For the first time to our knowledge, it can be observed that absorption efficiency is proportional to the PDMS flow rate for water/PDMS mixture. Moreover, it appears that high efficiencies obtained for absorption using PDMS as absorbing liquid $(\phi=1)$ do not require an amount of PDMS significantly higher than the amount of PDMS used in the water/PDMS mixture. Taking into account that water has only weak capacity to absorb hydrophobic VOCs, such a result leads us to question about the usefulness of using any water/PDMS mixtures to achieve an efficient absorption. Indeed, the use of water/PDMS mixtures involves designing an absorption column with a much larger diameter than that actually needed for an absorption in pure PDMS $(\phi=1)$. In a previous study devoted to a calculation procedure based on the EAC concept applied to a countercurrent gas/liquid absorber [8], a mathematical development generalized to any VOCs demonstrated that the amount of PDMS $\left(\mathrm{Q}_{\mathrm{PDMS}}=\phi \mathrm{Q}_{\mathrm{L}}\right)$ needed for pollutant absorption in a countercurrent gas/liquid absorber could be calculated as follows:

$$
Q_{P D M S}(\phi)=A Q_{G} \frac{H_{\text {water }}}{R T} \frac{\phi}{1+\phi\left(\left(H_{\text {water }} / H_{P D M S}\right)-1\right)}
$$

According to Eq. (15), the flow rate of PDMS depends directly on (i) the gas flow rate to be treated, (ii) the absorption factor chosen, (iii) the PDMS volume fraction chosen and (iv) VOC partition coefficient values. Based on Eq. (15), the ratio between the amount of PDMS used in the present study for absorption experiments and the amount of PDMS theoretically needed for 
an efficient absorption was calculated for each experiment (QPDMS min). An arbitrary value of the absorption factor $(\mathrm{A}=2)$ was chosen to apply Eq. (15). For all experiments carried out with PDMS as absorbing liquid $(\phi=1)$, the amount of PDMS used was higher than the amount required for an efficient absorption (up to 8 times for toluene), which explained that absorption efficiency was close to 1 especially at low gas flow rate. At high gas flow rate $Q_{G}=32 \mathrm{~m}^{3} \mathrm{~h}^{-1}$, the absorption efficiency are slightly lower (around 90\%), the amount of PDMS used being slightly higher than $100 \%$ of the amount required for absorption. This finding is mainly due to the increase of the number of VOC molecules that had to be transferred because the pollutant concentration was kept constant during experiment whatever the gas flow rate. For experiments carried out with water/PDMS mixture as absorbing liquid $(\phi=0,1)$, results are detailed in Fig. 14.

It is shown that the amount of PDMS used was around the amount required for an efficient absorption only for some experiments carried out at low gas flow rate $Q_{G}=18 \mathrm{~m}^{3} \mathrm{~h}^{-1}$. In these cases, absorption efficiencies higher than those measured were expected. For others experiments, results presented in Fig. 14 clearly illustrate that the amount of PDMS used in the water/PDMS mixture was not sufficient to ensure an efficient absorption. For a gas flow rate $Q_{G}=32 \mathrm{~m}^{3} \mathrm{~h}^{-1}$, the amount of PDMS used was lower than $40 \%$ of the amount required, which explains the decrease of the absorption efficiency in spite of the increase in $\mathrm{K}_{\mathrm{L}} \mathrm{a}$. As a result, the use of the EAC concept to analyze the experimental data confirms that water/PDMS mixtures should not be selected as absorbing liquid to treat DMDS and toluene. To summarize, it can be emphasized that it is unwise to use water/PDMS mixtures for mass transfer because an efficient absorption in a (90/10 v/v) water/PDMS mixture requires roughly the same amount of PDMS that the amount needed for an absorption in pure PDMS. The use of water/PDMS mixture for hydrophobic VOC absorption has drawbacks because the presence of water: (i) has only a weak influence on absorption efficiency; (ii) implies to design a column having a diameter higher than a column 
designed for pure PDMS; (iii) generates high pressure drops. Conversely, the use of an absorber contacting gas and pure PDMS phases presents the following advantages: (i) to reduce the size of the column (in diameter, and in height) and (ii) to obtain high absorption efficiencies at moderated values of L'/G' ratio which allows to limit pressure drops. Nonetheless, the use of pure PDMS leads to a decrease in $\mathrm{K}_{\mathrm{L}} \mathrm{a}$ in regards to values obtained for water/PDMS. However, this decrease is moderated and largely compensated by the affinity of VOCs for PDMS.

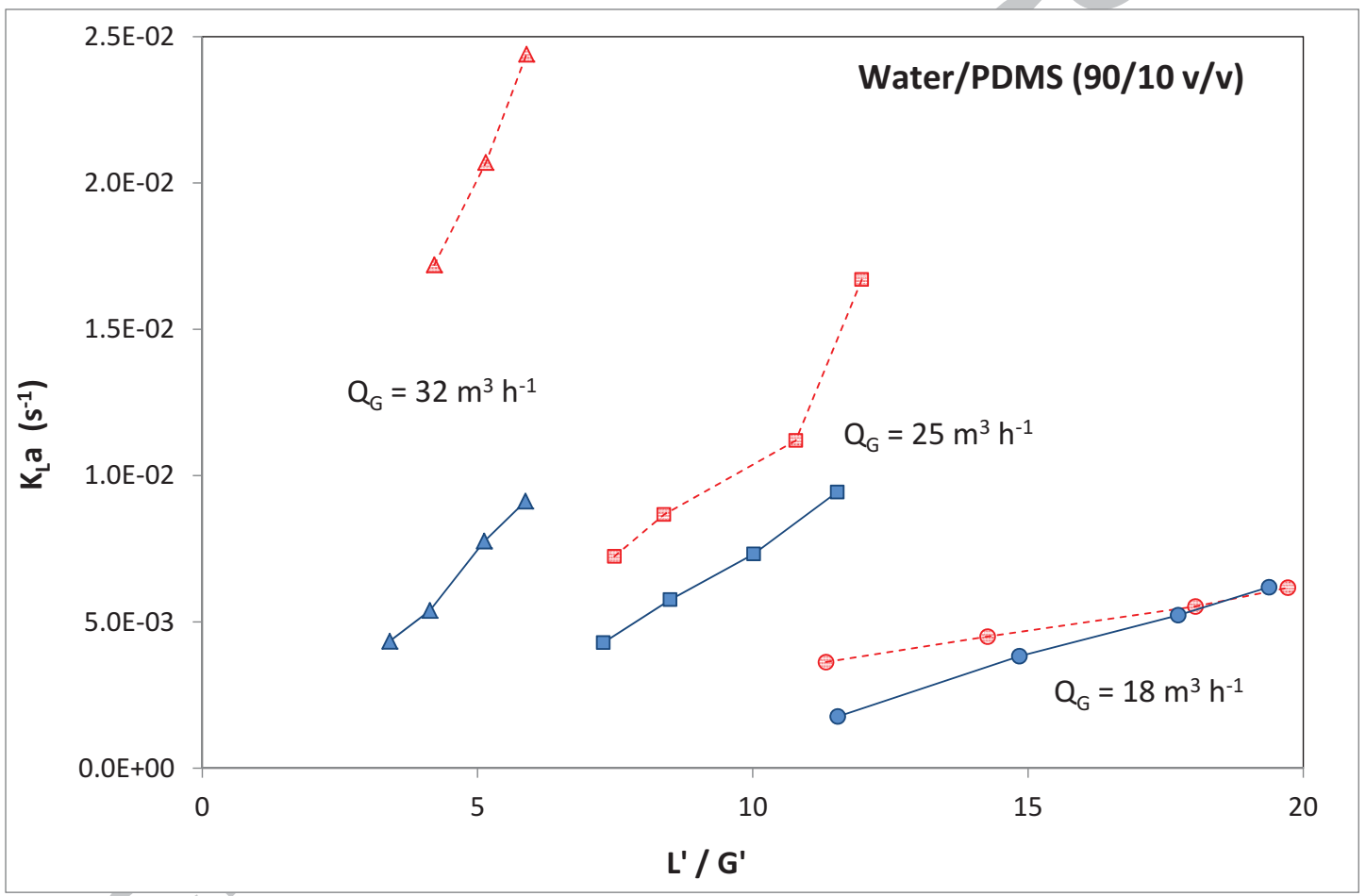

Fig. 12. Change in $\mathrm{K}_{\mathrm{L}}$ a vs gas flow rate for the water/PDMS mixture (continuous lines: toluene experiments; dashed lines: DMDS experiments). 

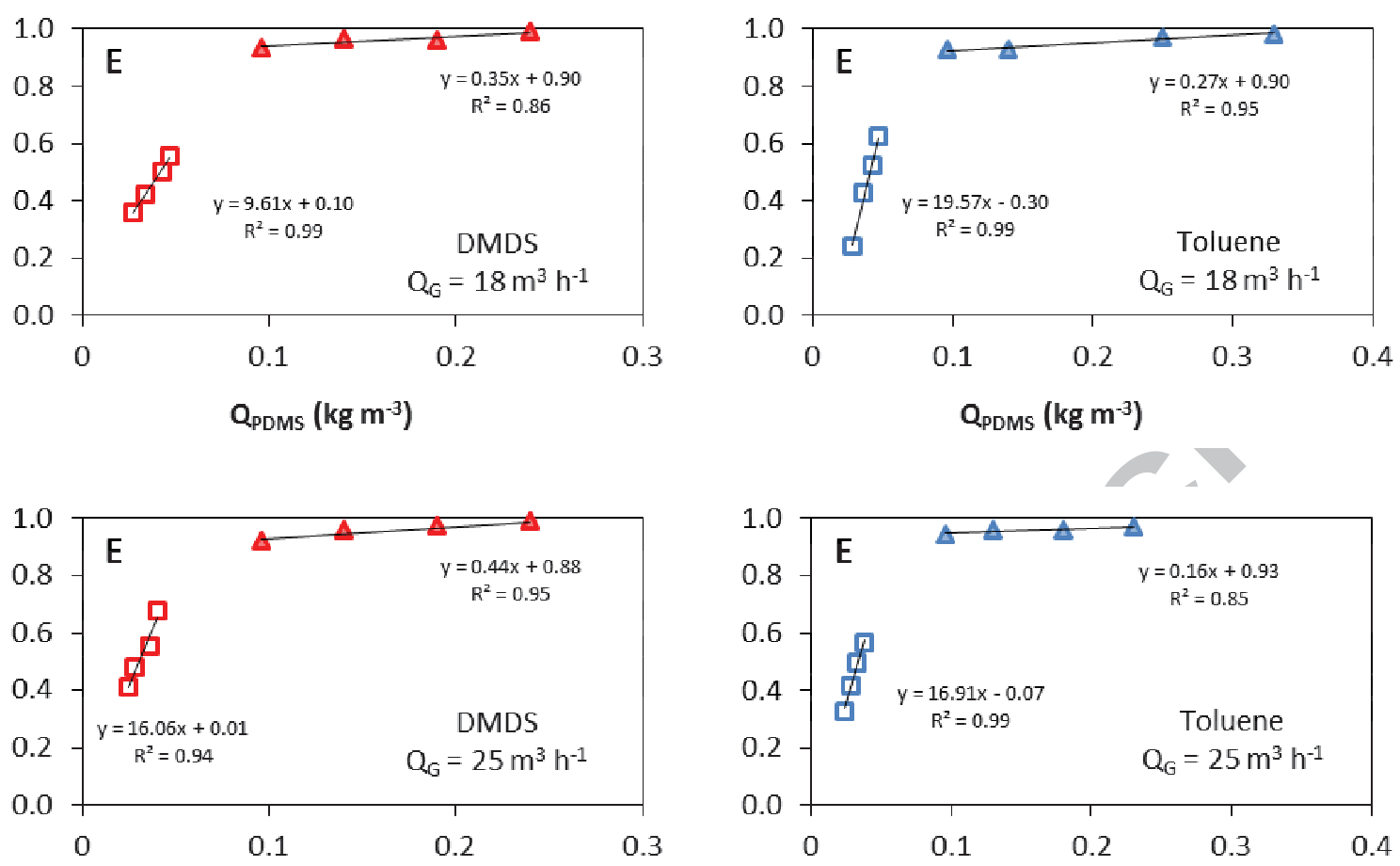

$\mathrm{Q}_{\text {PDMS }}\left(\mathrm{kg} \mathrm{m}^{-3}\right)$

$\mathrm{Q}_{\text {PDMS }}\left(\mathrm{kg} \mathrm{m}^{-3}\right)$

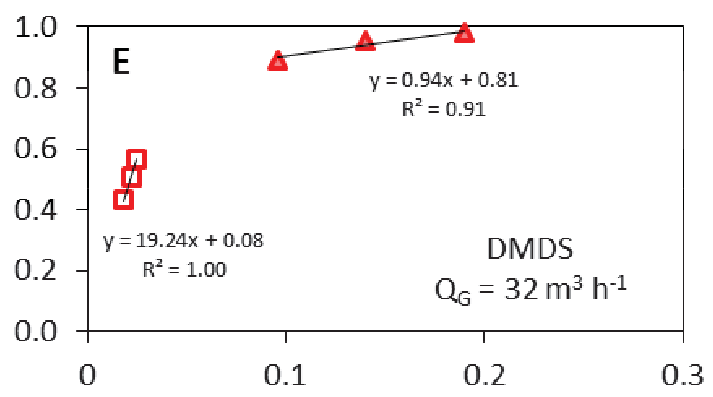

$\mathrm{Q}_{\mathrm{PDMS}}\left(\mathrm{kg} \mathrm{m}^{-3}\right)$

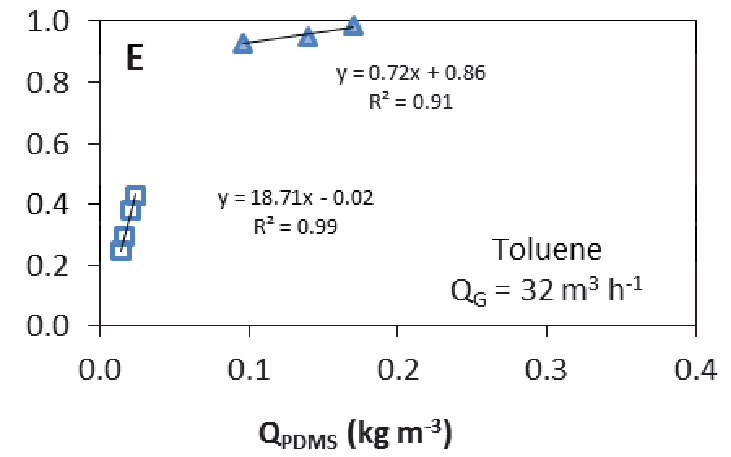

Fig. 13. Absorption efficiency (E) as a function of the amount of PDMS flowing in the column $\mathrm{Q}_{\mathrm{PDMS}}=\phi \mathrm{Q}_{\mathrm{L}}$. Left: DMDS experiments; open square: water/PDMS mixture $(90 / 10 \mathrm{v} / \mathrm{v})$; shaded triangle: $100 \%$ PDMS. Right: toluene experiments, open square: water/PDMS mixture (90/10 v/v); shaded triangle: $100 \%$ PDMS. 


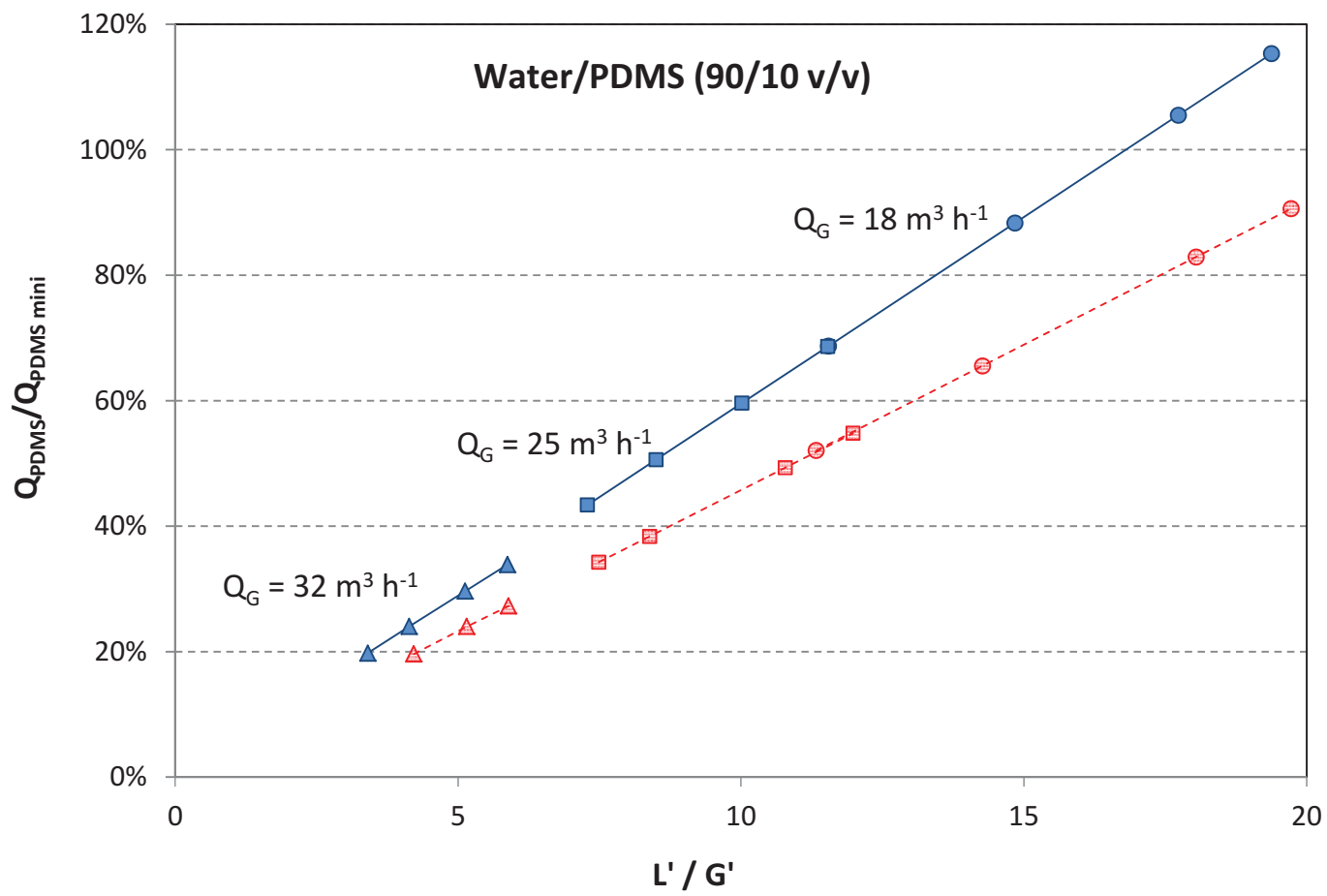

Fig. 14. Amount of PDMS flowing in the column divided by the amount of PDMS needed for absorption (Absorption factor $\mathrm{A}=2$; continuous lines: toluene experiments; dashed lines: DMDS experiments).

\section{Conclusion}

The Equivalent Absorption Capacity (EAC) concept was applied to a countercurrent gas-liquid contactor for the absorption of hydrophobic VOCs (DMDS and toluene). For the first time, it was emphasized from experimental data that the EAC concept describes satisfactorily the absorption behavior of the water/PDMS mixture. Moreover, the predicted results given in [8] showing that pure PDMS has to be used rather than a $(90 / 10 \mathrm{v} / \mathrm{v})$ water/PDMS mixture for hydrophobic VOC absorption were experimentally confirmed. Using pure PDMS as absorbing liquid (dynamic viscosity of $5 \mathrm{mPa}$ s), high absorption efficiencies (up to $99 \%$ ) were obtained for L'/G' value around 5. For these operating conditions, pressure drops in the packed column) and $\mathrm{K}_{\mathrm{L}}$ a values were around $1000 \mathrm{~Pa} \mathrm{~m}^{-1}\left(\mathrm{G}^{\prime}=1.06 \mathrm{~kg} \mathrm{~m}^{-2} \mathrm{~h}^{-1}\right.$ and $510^{-3} \mathrm{~s}^{-1}$, respectively. Consequently the 
biological treatment of air loaded with these pollutants should be highly effective at industrial scale in an integrated system coupling a countercurrent packed-bed absorption column combined to a Two-Phase Partitioning Bioreactor for pollutant degradation and PDMS regeneration.

\section{References}

[1] A.D. Dorado, E. Dumont, R. Muñoz, G. Quijano, A novel mathematical approach for the understanding and optimization of two-phase partitioning bioreactors devoted to air pollution control, Chem. Eng. J. 263 (2015) 239-248. doi:10.1016/j.cej.2014.11.014.

[2] E. Dumont, Y. Andrès, P. Le Cloirec, Mass transfer coefficients of styrene and oxygen into silicone oil emulsions in a bubble reactor, Chem. Eng. Sci. 61 (2006) 5612-5619. doi:10.1016/j.ces.2006.04.026.

[3] A. Kundu, E. Dumont, A.-M. Duquenne, H. Delmas, Mass Transfer Characteristics in Gasliquid-liquid System, Can. J. Chem. Eng. 81 (2003) 640-646. doi:10.1002/cjce.5450810341.

[4] G. Darracq, A. Couvert, C. Couriol, A. Amrane, D. Thomas, E. Dumont, et al., Silicone oil: An effective absorbent for the removal of hydrophobic volatile organic compounds, J. Chem. Technol. Biotechnol. 85 (2010) 309-313. doi:10.1002/jctb.2331.

[5] D.W. Green, R.H. Perry, Perry's Chemical Engineers' Handbook, Eighth Edition, 8th ed., McGraw-Hill Professional, New York, 2007.

[6] J. Mackowiak, Fluid Dynamics of Packed Columns: Principles of the Fluid Dynamic Design of Columns for Gas/Liquid and Liquid/Liquid Systems, 2010 edition, Springer, Heidelberg ; New York, 2010.

[7] E. Dumont, G. Darracq, A. Couvert, C. Couriol, A. Amrane, D. Thomas, et al., Hydrophobic VOC absorption in two-phase partitioning bioreactors; influence of silicone oil volume fraction on absorber diameter, Chem. Eng. Sci. 71 (2012) 146-152. doi:10.1016/j.ces.2011.12.017.

[8] E. Dumont, G. Darracq, A. Couvert, C. Couriol, A. Amrane, D. Thomas, et al., VOC absorption in a countercurrent packed-bed column using water/silicone oil mixtures: Influence of silicone oil volume fraction, Chem. Eng. J. 168 (2011) 241-248. doi:10.1016/j.cej.2010.12.073.

[9] E. Dumont, G. Darracq, A. Couvert, C. Couriol, A. Amrane, D. Thomas, et al., Determination of partition coefficients of three volatile organic compounds (dimethylsulphide, dimethyldisulphide and toluene) in water/silicone oil mixtures, Chem. Eng. J. 162 (2010) 927-934. doi:10.1016/j.cej.2010.06.045.

[10] M.C. Iliuta, F. Larachi, Solubility of dimethyldisulfide (DMDS) in aqueous solutions of $\mathrm{Fe}$ (III) complexes of trans-1,2-cyclohexanediaminetetraacetic acid (CDTA) using the static headspace method, Fluid Phase Equilibria. 233 (2005) 184-189. doi:10.1016/j.fluid.2005.05.004.

[11] D. Mackay, W.-Y. Shiu, K.-C. Ma, S.C. Lee, Handbook of Physical-Chemical Properties and Environmental Fate for Organic Chemicals, Second Edition, CRC Press, 2010. 
[12] B.H. Junker, T.A. Hatton, D.I.C. Wang, Oxygen transfer enhancement in aqueous/perfluorocarbon fermentation systems: I. experimental observations, Biotechnol. Bioeng. 35 (1990) 578-585. doi:10.1002/bit.260350605.

[13] B.H. Junker, D.I. Wang, T.A. Hatton, Oxygen transfer enhancement in aqueous/perfluorocarbon fermentation systems: II. Theoretical analysis, Biotechnol. Bioeng. 35 (1990) 586-597. doi:10.1002/bit.260350606.

[14] R.J. Littel, G.F. Versteeg, W.P.M. Van Swaaij, Physical absorption of CO2 and propene into toluene/water emulsions, AIChE J. 40 (1994) 1629-1638. doi:10.1002/aic.690401005.

[15] F. Heymes, P. Manno-Demoustier, F. Charbit, J.L. Fanlo, P. Moulin, A new efficient absorption liquid to treat exhaust air loaded with toluene, Chem. Eng. J. 115 (2006) 225231. doi:10.1016/j.cej.2005.10.011.

[16] R.K. Sinnott, Chemical Engineering Design, Fourth Edition: Chemical Engineering Volume 6, 4 edition, Butterworth-Heinemann, Amsterdam, 2005. 


\section{Highlights}

Absorption of hydrophobic VOCs in multiphase system gas/water/PDMS was considered

Experiments were carried out in a gas-liquid absorber filled with Raschig rings

Water, PDMS and a mixture of water/PDMS (90/10 v/v) were used as absorbing liquids

The EAC concept characterizes well the absorption behavior of water/PDMS mixture

Pure PDMS has to be used rather than the mixture for hydrophobic VOC absorption 